Technical Report 1078

\title{
Functional Capabilities of Four Virtual Individual Combatant (VIC) Simulator Technologies: An Independent Assessment
}

Robert J. Pleban, Jean L. Dyer, and Margaret S. Salter

U.S. Army Research Institute

Jamye B. Brown

Aubum University

Consortium Research Fellows Program

\author{
Infantry Forces Research Unit \\ Scott E. Graham, Chief
}

U.S. Army Research Institute for the Behavioral and Social Sclences 5001 Elesenhower Avenue, Alexandria, Virginia 22333-5600

February 1998

Army Project Number

Personnel Systems and 20262785A790

Performance Technology

Approved for public release; distribution is unlimited. 